\title{
Numerical modelling of a monopile for estimating the natural frequency of an offshore wind turbine
}

\author{
David Igoe $^{1}$, Luke J. Prendergast ${ }^{2}$, Breiffni Fitzgerald ${ }^{1}$ and Saptarshi Sarkar ${ }^{1}$ \\ ${ }^{1}$ Trinity College Dublin, Ireland \\ ${ }^{2}$ Delft University of Technology, Netherlands
}

\begin{abstract}
Monopiles are the most common foundation system for supporting Offshore Wind Turbines (OWT's), accounting for more than $80 \%$ of all OWT substructures installed in Europe to date [1]. Significant reductions in the cost of developing OWTs have been realized over the past few years, to the point where offshore wind can now be developed subsidy free in favorable locations. Optimizing the engineering design of these structures has played a key role in ensuring these cost reductions are possible. The largest uncertainty with respect to modelling the dynamic response of an OWT often relates to the geotechnical design. This paper examines the influence of soil-structure interaction on the dynamic response of an OWT structure. The below ground pile-soil behavior was modelled using (i) a conventional DNV (De Norske Veritas) ' $p-y$ ' approach and (ii) an advanced in-situ calibrated 3D FE geotechnical design approach. The results for the soil-structure interaction were inputted into a separate dynamic wind turbine model and the dynamic response using the two separate SSI approaches were compared.
\end{abstract}

Keywords: Monopiles, Numerical Modelling, Dynamics.

\section{Introduction}

Monopile foundations are single large diameter open-ended tubular steel piles, usually driven into the sea bed, which rely on the stiffness and strength of the surrounding soil to provide resistance against large environmental loads. In most practical situations, considerations of the dynamic response and natural frequency of the OWT structure will govern the monopile diameter.

The industry standard approach for the geotechnical design of monopiles in Europe are those recommended by DNV-GL [2], which uses a decoupled Winkler beam approach [3] where the lateral soil reaction is described by non-linear ' $p-y$ ' springs. The methods were calibrated using a limited number of pile tests performed on slender jacket piles with diameters less than $1 \mathrm{~m}$, and are now recognized as being unsuitable for predicting the response of large diameter monopiles [2]. Recent research ([4], [5], [6] and [7]) has attempted to address some of the shortfalls of the DNV approach and there is significant research effort in this area currently ongoing. This paper compares the dynamic response of an OWT structure where the below ground pile-soil behavior 
was modelled using (i) the conventional DNV ' $p-y$ ' approach and (ii) an advanced insitu calibrated 3D FE geotechnical design approach.

\section{$2 \quad$ Modelling}

\subsection{Site Location, Pile Geometry and Loading Conditions}

In order to model real-world offshore wind conditions, a soil profile from the Holland Kust (zuid) offshore wind farm zone in the Netherlands was chosen due to the public availability of the soil profile information and geotechnical testing reports. After a careful review, the HKZ2_BH03 location was selected as it was deemed to be representative of a typical North Sea medium dense to dense sand site. All soil parameters required for both the DNV approach and the 3D FE modelling were derived from the CPT profiles following the method defined by [4]. Based on the mean sea level at the location a water depth of $30 \mathrm{~m}$ was selected for analysis.

For the purposes of modelling the below mudline pile response, an initial approximate monopile geometry for the site was estimated as $7 \mathrm{~m}$ in diameter, $28 \mathrm{~m}$ embedment with a constant $70 \mathrm{~mm}$ wall thickness below mudline. Above the mudline, the monopile and wind-turbine geometry were developed based on a 5MW reference turbine as defined by NREL [8]. For this initial study, a fatigue damage equivalent horizontal load, $\mathrm{H}$, of $4000 \mathrm{kN}$ was assumed to act at an eccentricity, $e$, of $40 \mathrm{~m}$ above mudline.

\subsection{Monopile Modelling}

The 3D FE modelling was undertaken using a static analysis in Plaxis 3D 2017 software. The pile was modelled in half space to reduce computation time. After a sensitivity analysis to optimize the model geometry, the boundaries were set at $\pm 60 \mathrm{~m}$ in the $\mathrm{y}$-axis (direction of loading), 0 to $+30 \mathrm{~m}$ in the $\mathrm{x}$-axis and $+40 \mathrm{~m}$ to $-50 \mathrm{~m}$ in the $\mathrm{z}$-axis (with mudline defined at $+0 \mathrm{~m}$ ). The soil elements were modelled as ten-node tetrahedral elements. The pile wall was modelled using six-node plate elements with interface elements added to allow a reduction in interface shear strength by a factor, $\mathrm{R}_{\text {inter, }}$ of 0.7 . The pile plates were modelled as linear elastic elements with a Young's Modulus, $E$ of $210 \mathrm{GPa}$, Poisson's ratio, $v$ of 0.3 and a unit weight, $\gamma$ of $77 \mathrm{kN} / \mathrm{m}^{3}$. The Hardening Soil (HS) model as defined by Schanz [9] was used to define the soil response. All the required soil parameters for this model were derived from the CPT profile following the procedure defined in [4], which has been validated against a suite of monopile field tests. Once the 3D FE analysis was successfully completed, the soil reactions were extracted using the procedure described in [4] and defined in terms of linearized springs for use in the dynamic turbine model using a Matlab code.

For comparison with the 3D FE, the DNV ' $p-y$ ' approach was also considered (for brevity, details of the formulation of DNV approach will not be discussed in this paper). To summarize the approach taken, the DNV cyclic $p-y$ curves were applied in a 1D FE Winkler beam model using a static solver developed in Matlab (similar to the commercial LPile software). Under the applied fatigue loading $(\mathrm{H}=4000 \mathrm{kN})$, the secant 
stiffness of each non-linear $p-y$ soil spring was then output from the monopile model for use as a linearized spring stiffness in a full dynamic coupled OWT model.

The dynamic wind turbine model used was similar to that described in detail in [10], [11]. The monopile and tower elements were formulated using four-degree-of-freedom (4-DOF) Euler-Bernoulli beam elements. Each element was $1 \mathrm{~m}$ in length and the individual elements are assembled to create global matrices for the full system. The soil was modelled by means of linear Winkler springs [12] attached to each embedded node of the monopile. The soil springs were linearized from the static monopile analyses as described previously. The nacelle was incorporated by means of a lumped mass attached do the final node of the tower-top beam. The undamped natural frequencies were extracted by means of solution to the Eigenproblem [13], obtained by solving for the eigenvalues of a system matrix, $[\mathrm{D}]$, defined as $[\mathrm{M}]^{-1}[\mathrm{~K}]$.

\section{Results / Conclusions}

The displacement and linearized stiffness profiles, output from the 3D FE and DNV $p$ $y$ static loading analyses are shown in Figure 1. It is evident that the 3D FE provides a stiffer pile response, especially near the pile toe, albeit with a similar linear stiffness over the top $10 \mathrm{~m}$. Calculations of the natural frequency of the OWT system from the dynamic turbine model suggest a $1.03 \%$ increase in first natural frequency using linearized stiffness values from the 3D FE approach when compared with the DNV $p-y$ approach. Further research is ongoing to assess the accuracy of the dynamic modelling approaches and to assess effects of using non-linear springs on the first natural frequency of the OWT system.
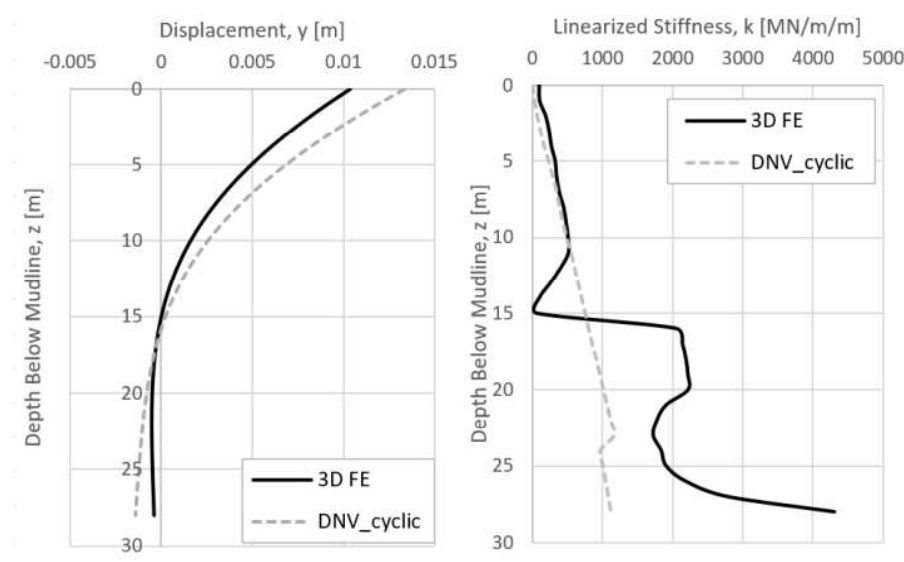

Fig. 1. (a) Displacement and (b) Linearized Stiffness Profiles from Static Monopile Models 


\section{References}

[1] Wind Europe, "Offshore wind in Europe - Key Statistics and Trends 2017," Wind Europe, 2017. [Online]. Available: https://windeurope.org/wpcontent/uploads/files/about-wind/statistics/WindEurope-Annual-OffshoreStatistics-2017.pdf.

[2] DNV.GL, "DNVGL-ST-0126: Support structures for wind turbines," Dnv Gl As, no. April 2016, 2016.

[3] E. Winkler, "Theory of elasticity and strength," in Dominicus Prague, 1867.

[4] G. Murphy, D. Igoe, P. Doherty, and K. G. Gavin, "3D FEM approach for laterally loaded monopile design," Comput. Geotech., p. In Press, 2018.

[5] B. W. Byrne et al., "New design methods for large diameter piles under lateral loading for offshore wind applications," in Frontiers in Offshore Geotechnics III - Proceedings of the 3rd International Symposium on Frontiers in Offshore Geotechnics, ISFOG 2015, 2015.

[6] B. W. Byrne et al., "Field testing of large diameter piles under lateral loading for offshore wind applications," in Geotechnical Engineering for Infrastructure and Development - Proceedings of the XVI European Conference on Soil Mechanics and Geotechnical Engineering, ECSMGE 2015, 2015, vol. 3.

[7] B. Byrne et al., "PISA: New Design Methods for Offshore Wind Turbine Monopiles (Keynote)," in International Conference on Offshore Site Investigations and Geotechnics, 2017.

[8] J. Jonkman, S. Butterfield, W. Musial, and G. Scott, "Definition of a 5-MW Reference Wind Turbine for Offshore System Development," no. February, 2009.

[9] T. Schanz, a Vermeer, and P. Bonnier, "The hardening soil model: formulation and verification," Beyond 2000 Comput. Geotech. 10 years PLAXIS Int. Proc. Int. Symp. beyond 2000 Comput. Geotech. Amsterdam Netherlands 1820 March 1999, p. 281, 1999.

[10] L. J. Prendergast, K. Gavin, and P. Doherty, "An investigation into the effect of scour on the natural frequency of an offshore wind turbine," Ocean Eng., vol. 101, 2015.

[11] L. J. Prendergast, C. Reale, and K. Gavin, "Probabilistic examination of the change in eigenfrequencies of an offshore wind turbine under progressive scour incorporating soil spatial variability," Mar. Struct., vol. 57, pp. 87-104, 2018.

[12] S. C. Dutta and R. Roy, "A critical review on idealization and modeling for interaction among soil-foundation-structure system," Comput. Struct., vol. 80, pp. 1579-1594, 2002.

[13] J. P. R.W. Clough, Dynamics of structures. 1993. 